\title{
Extracorporeal membrane oxygenation as a bridge to lung transplantation is about more than just surviving
}

Dirk Van Raemdonck, MD, PhD ${ }^{\mathrm{a}, \mathrm{b}}$ Fabienne Dobbels, MSc, $\mathrm{PhD},{ }^{\mathrm{c}}$ and Greet Hermans, $\mathrm{MD}, \mathrm{PhD}{ }^{\mathrm{d}, \mathrm{e}}$
In his blog post, "When Life Is About More Than Just Survival," Tom Eggebrecht, ${ }^{1}$ author of the paperback Fully and Creatively Alive: How to Live a More Joyfully Fulfilling Life, writes about people who successfully pursued their passions and followed their dreams in many and various ways. We quote from this post ${ }^{1}$ : "There's nothing like Florida mornings. They teem with life. Every morning when I ride my bike on our local trail I get to observe the beautiful sunrise. I see the mist rising off of the open fields. And I get to ride through lush green woods filled with banyan trees, palms, and deep green vegetation. It's the time of day when the wildlife is waking up. I see hawks, turkeys, squirrels, rabbits, snakes, egrets, osprey, and even an occasional alligator. What strikes me every morning is that all the birds and animals are waking up simply to survive another day. It reminds me that for us human beings life is so much more than simply trying to survive."

Extracorporeal membrane oxygenation (ECMO) is increasingly being used as a bridge to lung transplant (LTx) in patients who deteriorate from hypercapnic and/or hypoxic respiratory insufficiency or from right heart failure with pulmonary hypertension. ${ }^{2}$ ECMO facilitates early ambulation (Figure 1) and may mitigate detrimental intensive care unit complications, including weakness, delirium, and ventilator-associated pneumonia. ${ }^{3}$ Outcome in patients put on ECMO support as a bridge to $\mathrm{LTx}^{3-5}$ or as a rescue therapy for primary graft dysfunction after LTx ${ }^{6}$ is typically defined in terms of survival and pulmonary function. Little is known, however, about the impact of receiving ECMO support on patients' physical and mental well-being.

In this issue of the Journal, Kolaitis and coworkers ${ }^{7}$ compared the health-related quality of life and depressive symptoms in 17 patients on ECMO support as a bridge to LTx with those of 48 patients hospitalized at the time of of life. beautiful sunrise.

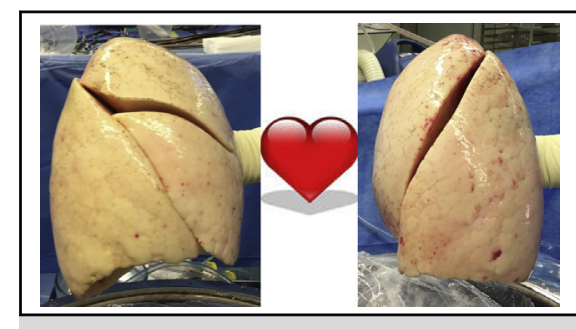

A pair of healthy donor lungs on their way to a happy recipient. (Copyright D.V.R.)

\section{Central Message}

Candidates successfully bridged on ECMO to first lung transplant have comparable survival to those without ECMO and also similar improvements in health-related quality of life and depressive symptoms.

See Article page 440.

transplant but not on ECMO support and with those of 124 transplant candidates who were called in from home. One-year survival (97\%) was the same in all groups. Quality of life and depressive symptoms significantly improved from pre-LTx to post-LTx within all groups. Importantly, patients on ECMO support reached similar patientreported outcomes to those of patients without ECMO. Kolaitis and coworkers ${ }^{7}$ therefore concluded that patients in need of ECMO to survive the waiting period for a suitable organ should not be precluded from this rescue therapy.

Apart from one other study with comparable conclusions reported by the Groningen Lung Transplant Group, which used a visual analog scale for assessment of quality of life, ${ }^{8}$ the study of Kolaitis and coworkers ${ }^{7}$ is a unique report. This is the largest study to date on patient-reported outcomes after ECMO. Kolaitis and coworkers ${ }^{7}$ are to be applauded for the excellent survival obtained in this high-risk population. Their results should reassure intensivists, cardiothoracic surgeons, and allied health professionals that their efforts to keep these critically ill patients alive in the intensive care unit for days and weeks is worthwhile, not only in terms of survival but also with respect to their patients' post-LTx quality

ECMO as a bridge to LTx is about more than just surviving. It is about hoping to ride a bike again to observe the 

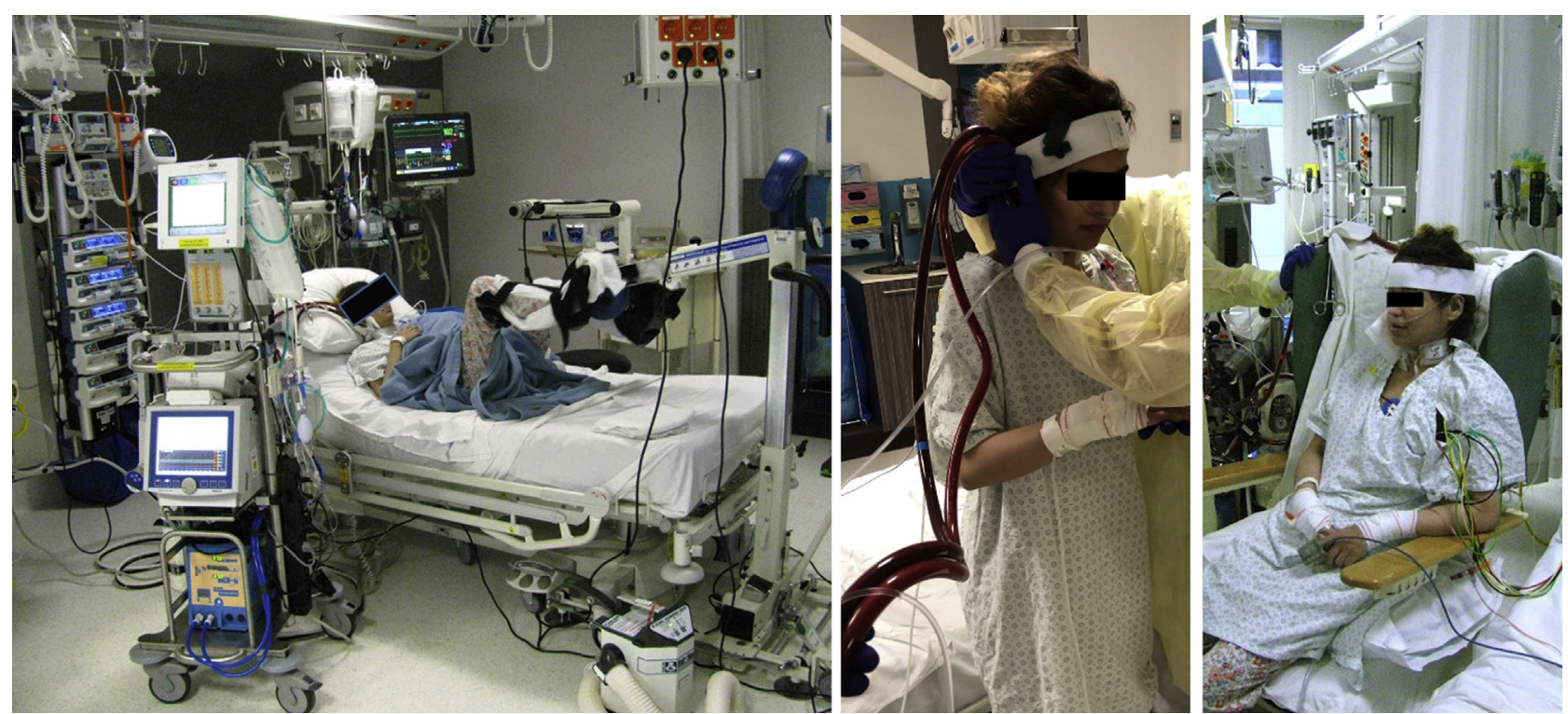

FIGURE 1. A 26-year-old transplant candidate with end-stage cystic fibrosis at the University Hospitals Leuven (Leuven, Belgium) ambulating on awake venovenous extracorporeal membrane oxygenation support while awaiting a healthy donor lung offer.

\section{References}

1. Eggebrecht T. When life is about more than just survival. Available at: http://www. tomeggebrecht.com/life-just-survival. Accessed February 28, 2018.

2. Loor G, Simpson L, Parulekar A. Bridging to lung transplantation with extracorporeal circulatory support: when or when not? J Thorac Dis. 2017;9:3352-61.

3. Biscotti M, Gannon WD, Agerstrand C, Abrams D, Sonett J, Brodie D, et al. Awake extracorporeal oxygenation as bridge to lung transplantation: a 9-year experience. Ann Thorac Surg. 2017;104:412-9.

4. Hoetzenecker K, Donahoe L, Yeung JC, Azad S, Fan E, Ferguson ND, et al. Extracorporeal life support as a bridge to lung transplantation - experience of a highvolume transplant center. J Thorac Cardiovasc Surg. 2017;155:1316-28.

5. Ius F, Natanov R, Salman J, Kuehn C, Sommer W, Avsar M, et al. Extracorporeal membrane oxygenation as a bridge to lung transplantation may not impact overall mortality risk after lung transplantation: results from a 7-year single-centre experience. Eur J Cardiothorac Surg. February 12, 2018 [Epub ahead of print].

6. Hartwig MG, Walczak R, Lin SS, Davis RD. Improved survival but marginal allograft function in patients treated with extracorporeal membrane oxygenation after lung transplantation. Ann Thorac Surg. 2012;93:366-71.

7. Kolaitis NA, Soong A, Shrestha P, Zhuo H, Neuhaus J, Katz PP, et al. Improvement in patient reported outcomes after lung transplantation is not impacted by the use of extracorporeal membrane oxygenation as a bridge to transplantation. J Thorac Cardiovasc Surg. 2018;156:440-8.

8. Lansink-Hartgring AO, van der Bij W, Verschuuren EA, Erasmus ME, de Vries AJ, Vermeulen KM, et al. Extracorporeal life support as a bridge to lung transplantation: a single-center experience with an emphasis on health-related quality of life. Respir Care. 2017;62:588-94. 